\title{
RESEARCH BRIEF \\ Prevalence of Multiple Chronic Conditions Among US Adults, 2018
}

\author{
Peter Boersma, $\mathrm{MPH}^{1}$; Lindsey I. Black, $\mathrm{MPH}^{1}$; Brian W. Ward, $\mathrm{PhD}^{2}$
}

Accessible Version: www.cdc.gov/pcd/issues/2020/20_0130.htm

Suggested citation for this article: Boersma P, Black LI, Ward BW. Prevalence of Multiple Chronic Conditions Among US Adults, 2018. Prev Chronic Dis 2020;17:200130. DOI: https:// doi.org/10.5888/pcd17.200130.

\section{PEER REVIEWED}

\section{Summary}

What is already known on this topic?

Research has shown increases in the overall percentage of US adults with multiple chronic conditions, as well as variation by population subgroups.

What is added by this report?

In $2018,51.8 \%$ of US adults had at least 1 chronic condition, and $27.2 \%$ had multiple chronic conditions. Prevalence was highest among women, non-Hispanic white adults, adults aged 65 or older, and those living in rural areas.

What are the implications for public health practice?

These results may inform efforts to track and monitor multiple chronic conditions among the US population.

\section{Abstract}

This analysis provides prevalence estimates of diagnosed single and multiple $(\geq 2)$ chronic conditions among the noninstitutionalized, civilian US adult population. Data from the 2018 National Health Interview Survey (NHIS) were used to estimate percentages for US adults by selected demographic characteristics. More than half (51.8\%) of adults had at least 1 of 10 selected diagnosed chronic conditions (arthritis, cancer, chronic obstructive pulmonary disease, coronary heart disease, current asthma, diabetes, hepatitis, hypertension, stroke, and weak or failing kidneys), and $27.2 \%$ of US adults had multiple chronic conditions.

\section{Objective}

In $2012,25.5 \%$ of US adults had multiple ( $\geq 2)$ diagnosed chronic conditions among 10 different conditions: arthritis, cancer, chron- ic obstructive pulmonary disease (COPD), coronary heart disease, current asthma, diabetes, hepatitis, hypertension, stroke, and weak or failing kidneys $(1,2)$. Compared with adults without chronic conditions, adults with multiple chronic conditions have worse health-related quality of life, higher health care costs, and increased risk of death (3-5). Using 2018 National Health Interview Survey (NHIS) data, we provide estimates of the prevalence of single and multiple chronic conditions among US adults.

\section{Methods}

The NHIS is a cross-sectional, in-person, nationally representative health survey of the US civilian noninstitutionalized population conducted by the National Center for Health Statistics (NCHS). Data on chronic conditions are part of the sample adult component; the sample adult is randomly selected from all adults in the family. This analysis includes 25,417 sample adults from the 2018 NHIS (final response rate, 53.1\%) (6).

The chronic conditions included in this study were 10 conditions from a list of 20 identified by the US Department of Health and Human Services to foster a more consistent and standardized approach to measuring the occurrence of chronic conditions (2). Adults were asked if they had ever been told by a doctor or health care provider that they had hypertension, coronary heart disease, stroke, diabetes, cancer, arthritis, or hepatitis; had experienced weak or failing kidneys during the past 12 months; currently had asthma; or had COPD (ie, ever had emphysema, ever had COPD, and/or had chronic bronchitis in the past 12 months) $(1,7)$. Based on their responses, adults were identified as having 0,1 , or $\geq 2$ conditions. Estimates were generated using SUDAAN software version 11.0.1 (RTI International) to account for the complex sample design of the NHIS; $95 \%$ confidence intervals were generated by using the Korn-Graubard method. All prevalence estimates met NCHS reliability standards (8). Urbanicity of residence was dichotomized based on the 2013 NCHS urban-rural classification scheme for counties (9). Two-tailed significance tests were performed to determine whether significant differences exist for percentages of multiple chronic conditions by demographic subgroup. Significance was set at $P<.05$. 


\section{Results}

In $2018,51.8 \%$ (129 million) of civilian, noninstitutionalized adults had been diagnosed with at least 1 of 10 selected chronic conditions. More specifically, 24.6\% (61 million) of adults had 1 chronic condition, and $27.2 \%$ (68 million) had $\geq 2$ chronic conditions (Table).

Prevalence of multiple chronic conditions differed by population subgroups. Prevalence was higher among women $(28.4 \%)$ than men $(25.9 \%)$ and increased with advancing age. Prevalence of multiple chronic conditions was highest among non-Hispanic white adults (30.6\%) and lowest among non-Hispanic Asian (16.4\%) and Hispanic adults (17.7\%). Among adults aged 18-64 years, the prevalence of multiple chronic conditions was higher among adults on public insurance $(27.6 \%)$ than either adults on private insurance $(15.7 \%)$ or uninsured adults $(11.6 \%)$, and the prevalence differed significantly across all insurance subgroups. Among adults aged 65 or older, the prevalence of multiple chronic conditions was highest among adults with both Medicare and Medicaid ("Dual eligible") (76.9\%), lowest among adults on Medicare only (excluding Medicare Advantage) (58.5\%), and differed significantly across all insurance subgroups with the exception of those with private (63.2\%) and Medicare Advantage coverage $(63.0 \%)$. Examination by urbanicity indicated that those living in rural areas $(34.8 \%)$ had a higher prevalence of multiple chronic conditions compared with those living in urban areas $(26.1 \%)$.

\section{Discussion}

In 2018, just over a quarter (27.2\%) of US adults had multiple chronic conditions. This finding is consistent with previous research that found the prevalence to be $25.5 \%$ in $2012,26.0 \%$ in 2010 , and $21.8 \%$ in $2001(1,10)$. In 2018, prevalence of multiple chronic conditions was higher among women, non-Hispanic white adults, older adults, adults aged 18-64 on Medicaid, dual-eligible adults (Medicare and Medicaid), and adults in rural areas. These disparities were similar to those identified in previous research, which found a higher prevalence among women, older adults, and adults on public insurance but did not examine prevalence by location of residence or separate insurance status by age $(1,10)$.

This study has several limitations. First, although NHIS data are nationally representative of the civilian, noninstitutionalized population, the exclusion of institutionalized adults, particularly those in long-term care settings, may lead to underreporting of the prevalence of chronic conditions. Second, NHIS captures only 10 of the 20 chronic conditions outlined by the US Department of Health and Human Services (2). However, it is important to note that this is the first report on overall prevalence to use the expanded definition of COPD, which now includes a question that asks explicitly about diagnosed COPD in addition to questions that ask about diagnosed emphysema and chronic bronchitis (7). Third, data are based on self-report of diagnosed conditions, which may result in recall bias. Lastly, NHIS collects data only on diagnosed conditions, so undiagnosed conditions are not recorded.

We found that nearly $30 \%$ of the US adult population has multiple chronic conditions. This work builds on previous research and provides current estimates of the prevalence using a nationally representative sample. These findings may allow for an expanded understanding of the epidemiology of multiple chronic conditions by providing estimates of overall burden and identifying high-risk subgroups.

\section{Acknowledgments}

The views expressed in this article are those of the authors and do not necessarily represent the official views of the NCHS, the Centers for Disease Control and Prevention, or the US Department of Health and Human Services. No financial support was received for this work. No copyrighted instruments or tools were used for this research.

\section{Author Information}

Corresponding Author: Peter Boersma, MPH, National Center for Health Statistics, 3311 Toledo Rd, Room 5216, Hyattsville, MD 20782. Telephone: 301-458-4101. E-mail: pboersma@cdc.gov.

Author Affiliations: ${ }^{1}$ Division of Health Interview Statistics, National Center for Health Statistics, Hyattsville, Maryland. ${ }^{2}$ Division of Health Care Statistics, National Center for Health Statistics, Hyattsville, Maryland.

\section{References}

1. Ward BW, Schiller JS, Goodman RA. Multiple chronic conditions among US adults: a 2012 update. Prev Chronic Dis 2014;11:130389.

2. Goodman RA, Posner SF, Huang ES, Parekh AK, Koh HK. Defining and measuring chronic conditions: imperatives for research, policy, program, and practice. Prev Chronic Dis 2013;10:120239.

3. Agborsangaya CB, Lau D, Lahtinen M, Cooke T, Johnson JA. Health-related quality of life and healthcare utilization in multimorbidity: results of a cross-sectional survey. Qual Life Res 2013;22(4):791-9.

The opinions expressed by authors contributing to this journal do not necessarily reflect the opinions of the U.S. Department of Health and Human Services, the Public Health Service, the Centers for Disease Control and Prevention, or the authors' affiliated institutions. 
4. Anderson G. Chronic care: making the case for ongoing care. Princeton (NJ): Robert Wood Johnson Foundation; 2010. https://www.rwjf.org/en/library/research/2010/01/chroniccare.html. Accessed January 6, 2020.

5. Lee TA, Shields AE, Vogeli C, Gibson TB, Woong-Sohn M, Marder WD, et al. Mortality rate in veterans with multiple chronic conditions. J Gen Intern Med 2007;22(Suppl 3):403-7.

6. Survey Description. National Health Interview Survey, 2018. Hyattsville (MD): National Center for Health Statistics; 2019. https://www.cdc.gov/nchs/nhis/data-questionnairesdocumentation.htm. Accessed July 29, 2020.

7. Ward BW, Nugent CN, Blumberg SJ, Vahratian A. Measuring the prevalence of diagnosed chronic obstructive pulmonary disease in the United States using data from the 2012-2014 National Health Interview Survey. Public Health Rep 2017; 132(2):149-56.

8. Parker JD, Talih M, Malec DJ, Beresovsky V, Carroll M, Gonzales JF Jr, et al.National Center for Health Statistics data presentation standards for proportions. Vital Health Stat 2 2017;(175):1-22.

9. Ingram DD, Franco SJ. NCHS urban-rural classification scheme for counties. Vital Health Stat 2 2013;2014(166).

10. Ward BW, Schiller JS. Prevalence of multiple chronic conditions among US adults: estimates from the National Health Interview Survey, 2010. Prev Chronic Dis 2013; 10:120203.

The opinions expressed by authors contributing to this journal do not necessarily reflect the opinions of the U.S. Department of Health and Human Services, the Public Health Service, the Centers for Disease Control and Prevention, or the authors' affiliated institutions. 


\section{Table}

Table. Percentage and Number of US Adults Aged 18 Years or Older With Chronic Conditions, ${ }^{a}$ by Select Characteristics, United States, 2018

\begin{tabular}{|c|c|c|c|c|c|c|}
\hline \multirow[b]{2}{*}{ Characteristic } & \multicolumn{2}{|c|}{0 Chronic Conditions } & \multicolumn{2}{|c|}{1 Chronic Condition } & \multicolumn{2}{|c|}{$\geq 2$ Chronic Conditions } \\
\hline & $\begin{array}{l}\text { \% Population }{ }^{\text {b }} \\
(95 \% \mathrm{Cl})\end{array}$ & $\mathbf{N}$ & $\begin{array}{l}\text { \% Population }{ }^{b} \\
(95 \% \mathrm{Cl})\end{array}$ & $\mathbf{N}$ & $\begin{array}{l}\text { \% Population }{ }^{\mathrm{b}} \\
(95 \% \mathrm{Cl})\end{array}$ & $\mathbf{N}$ \\
\hline Total $^{c}$ & $48.2(47.3-49.1)$ & 120,230 & $24.6(23.9-25.3)$ & 61,371 & $27.2(26.5-27.9)$ & 67,854 \\
\hline \multicolumn{7}{|c|}{$\operatorname{Sex}^{d}$} \\
\hline Male & $49.8(48.5-51.0)$ & 59,921 & $24.4(23.4-25.4)$ & 29,346 & $25.9(24.9-26.9)$ & 31,175 \\
\hline Female & $46.7(45.6-47.9)$ & 60,309 & $24.8(23.9-25.7)$ & 32,025 & $28.4(27.5-29.4)$ & 36,679 \\
\hline \multicolumn{7}{|c|}{ Race/ethnicity ${ }^{\mathrm{e}}$} \\
\hline Non-Hispanic White & $43.8(42.7-44.8)$ & 68,839 & $25.6(24.8-26.4)$ & 40,248 & $30.6(29.7-31.6)$ & 48,202 \\
\hline Non-Hispanic Black & $47.6(45.0-50.2)$ & 13,845 & $25.4(23.3-27.6)$ & 7,390 & $27.0(25.0-29.1)$ & 7,855 \\
\hline Non-Hispanic Asian & $62.0(58.6-65.2)$ & 9,400 & $21.6(19.0-24.4)$ & 3,280 & $16.4(14.0-19.0)$ & 2,486 \\
\hline Hispanic & $61.5(59.3-63.5)$ & 25,042 & $20.8(19.1-22.5)$ & 8,478 & $17.7(16.2-19.3)$ & 7,230 \\
\hline \multicolumn{7}{|c|}{ Age, $y^{d}$} \\
\hline $18-44$ & $72.6(71.4-73.7)$ & 83,444 & $20.7(19.7-21.8)$ & 23,841 & $6.7(6.1-7.3)$ & 7,723 \\
\hline $45-64$ & $36.6(35.3-37.9)$ & 30,404 & $30.4(29.2-31.6)$ & 25,250 & $33.0(31.7-34.3)$ & 27,383 \\
\hline$\geq 65$ & $12.4(11.5-13.3)$ & 6,382 & $23.9(22.7-25.1)$ & 12,280 & $63.7(62.3-65.1)$ & 32,748 \\
\hline \multicolumn{7}{|c|}{ Health insurance coverage ${ }^{f}$} \\
\hline \multicolumn{7}{|l|}{ Age $18-64 y^{d}$} \\
\hline Private & $58.6(57.5-59.8)$ & 80,085 & $25.7(24.7-26.7)$ & 35,065 & $15.7(14.9-16.5)$ & 21,418 \\
\hline Public & $48.9(46.3-51.6)$ & 12,192 & $23.4(21.4-25.5)$ & 5,830 & $27.6(25.5-29.9)$ & 6,886 \\
\hline Uninsured & $66.8(64.3-69.3)$ & 17,059 & $21.6(19.4-23.9)$ & 5,511 & $11.6(10.1-13.2)$ & 2,995 \\
\hline \multicolumn{7}{|l|}{ Age $\geq 65 y^{g}$} \\
\hline Private & $12.4(11.1-13.8)$ & 2,633 & $24.4(22.6-26.3)$ & 5,190 & $63.2(61.2-65.3)$ & 13,451 \\
\hline Dual eligible & $6.8(4.6-9.6)$ & 239 & $16.4(13.0-20.1)$ & 577 & $76.9(72.5-80.8)$ & 2,713 \\
\hline Medicare Advantage & $11.9(10.2-13.6)$ & 1,556 & $25.2(22.9-27.6)$ & 3,300 & $63.0(60.3-65.6)$ & 8,257 \\
\hline Medicare only excluding Medicare Advantage & $16.1(13.6-18.8)$ & 1,280 & $25.4(22.2-28.9)$ & 2,020 & $58.5(54.8-62.1)$ & 4,645 \\
\hline \multicolumn{7}{|c|}{ Location of residence $^{d}$} \\
\hline Urban & $49.5(48.5-50.5)$ & 107,383 & $24.5(23.7-25.2)$ & 53,125 & $26.1(25.3-26.9)$ & 56,577 \\
\hline Rural & $39.7(37.3-42.1)$ & 12,847 & $25.5(23.8-27.2)$ & 8,246 & $34.8(32.8-37.0)$ & 11,277 \\
\hline
\end{tabular}

${ }^{a}$ Chronic conditions measured were arthritis, cancer, chronic obstructive pulmonary disease, coronary heart disease, current asthma, diabetes, hepatitis, hypertension, stroke, and weak/failing kidneys.

${ }^{\mathrm{b}}$ Population in 1,000 s.

${ }^{\mathrm{C}}$ Total 2018 US adult population: 249 million people. Numbers may not sum to group totals because of rounding.

${ }^{\mathrm{d}}$ Difference in estimates of multiple chronic conditions ( $\geq 2$ conditions) between all subcategories was significant at $P<.001$.

${ }^{\mathrm{e}}$ With the exception of Hispanic vs non-Hispanic Asian adults $(P=.37)$, all other differences in estimates of multiple chronic conditions among racial/ethnic groups were significant (all $P<.001$ except for between non-Hispanic White and non-Hispanic Black adults [P=.002]).

${ }^{\top}$ Health insurance coverage was based on a hierarchy of mutually exclusive categories (6).

${ }^{g}$ With the exception of private vs Medicare Advantage $(P=.88)$, all other differences in estimates of multiple chronic conditions among adults aged $\geq 65$ by insurance status were significant (all $P<.001$ except for between private and Medicare $[P=.02]$ and between Medicare Advantage and Medicare $[P=.04]$ ).

The opinions expressed by authors contributing to this journal do not necessarily reflect the opinions of the U.S. Department of Health and Human Services, the Public Health Service, the Centers for Disease Control and Prevention, or the authors' affiliated institutions. 